\title{
Bourdieu e as cenas musicais: limites e barreiras
}

\section{Bourdieu and the music scenes: limits and boundaries}

Marcelo Garson ${ }^{1}$ 


\section{Resumo}

Este artigo é uma reflexão acerca dos limites, barreiras e adaptações necessárias que os conceitos de Bourdieu relativos ao gosto e ao consumo cultural nos impõem quando investigamos objetos específicos. Nesse sentido, selecionamos cenas musicais como elemento de análise a fim de enxergar em que medida noções como campo, habitus e capital cultural e social dão conta de analisar as lógicas internas de expressões como essas, cada vez mais mutantes, efêmeras e híbridas.

Palavras-chave

Bourdieu, gosto, cenas musicais.

\section{Abstract}

This article reflects on the limits, obstacles and adaptations that Bourdieu's concepts on cultural taste and consumption require when investigating specific objects. In this vein, we chose musical scenes as our object of study in order to see to what extent notions such as field, habitus, cultural and social capitals are useful for analyzing the internal logics of these increasingly changing, ephemeral and hybrid expressions.

\section{Keywords}

Bourdieu, taste, music scenes. 
Como entender a diversidade de expressões musicais na contemporaneidade? As maneiras de classificar as sonoridades emergentes parecem obedecer a uma lógica muito pouco clara. Em 2008 falávamos em disco-punk, mais recentemente, em nova MPB. Nomenclaturas tradicionais são repaginadas, o consagrado se funde ao pop e um novo público resgata e remodela os clássicos. Ao que parece, a cultura contemporânea permite o cruzamento irrestrito e em escala global de todo tipo de sonoridade, produzindo novos estilos cujo ciclo de ascensão e queda é cada vez mais rápido. Qual é o sentido dessa diversidade? Ou melhor, será que a noção de "sentido" e "lógica" ainda é útil para compreendermos a paisagem musical contemporânea?

Influenciados pelo referencial teórico pós-moderno, a partir dos anos noventa, um grupo de pesquisadores chamados pós-subculturalistas afirmou, em linhas gerais, que a busca pelo sentido nas expressões juvenis contemporâneas estava destinada ao fracasso. Seu objetivo era se opor a nomes como Stuart Hall (1976) e Phil Cohen (1997), que, na década de 60, utilizaram as classes sociais e a noção de autenticidade como chaves para compreender a eclosão, e posterior incorporação ao mercado, das subculturas da classe trabalhadora - teds, mods, rockers, skinheads - surgidas na Inglaterra do pós-guerra.

Na perspectiva pós-subcultural, a paisagem contemporânea caracterizada pela presença dominante da mídia e explosão de signos de consumo faz que a imagem reine soberana. Sentido, significado, coerência e, principalmente, autenticidade tornam-se palavras do passado. Resta celebrar a diversidade, fluidez e efemeridade dos signos e rituais que singularizam cada grupo juvenil (BENNET, 1999; MUGGLETON, 2003). Poucos termos sintetizam tão bem esse posicionamento quanto "supermercado de estilos", expressão que busca dar conta das infinitas possibilidades disponíveis hoje para criação de identidades fluidas, livres das regras e amarras que caracterizavam os modos de expressão característicos da modernidade (POLHEMUS, 2016).

No caso específico da música, Andy Bennet (1999), em sua etnografia da cena de música eletrônica de Glasgow, mostrou como, em um mesmo evento, 
diferentes sonoridades conviviam, misturando sucessos do passado com estilos do presente. Diante disso, a audiência, que não se segmentava por estilos musicais, estaria disposta a transitar e experimentar tudo. Para Bennet, isso era sintoma da ordem pós-moderna em sua fragmentação - diversidade, fluidez e falta de preocupação com a autenticidade. Essa última dimensão ficava ainda mais clara perante um grupo de jovens ingleses, filhos de asiáticos, que não viam incompatibilidade em seus gostos musicais; eles misturavam bhangra, um estilo tradicional de música indiana, e rock ocidental.

No entanto, essa suposta liberdade e pluralidade deve ser vista com ressalvas. A multiplicação de eleições, comunidades virtuais e fã-clubes mostram como a forma de classificar, valorar e organizar sonoridades ainda é importante na cultura contemporânea. A questão do gosto, portanto, torna-se fundamental. Nosso objetivo é colocá-la no centro de nossas preocupações, a fim de compreender a lógica que organiza as expressões musicais contemporâneas. Observando suas estruturas internas, investigaremos como se constroem hierarquias de valor cada vez mais complexas e mutantes. Nelas, ao contrário do que afirma a perspectiva pós-subcultural, a noção de autenticidade, a busca por "soar verdadeiro", ainda é fundamental.

Para defender nossa tese, valemo-nos da obra de Pierre Bourdieu (1985, $1989,1990,2007)$. Sua sociologia do gosto mostra como a aparente trivialidade inscrita nas escolhas que fazemos todos os dias em matéria de vestuário, alimentação e entretenimento esconde uma série de regras que operam à nossa revelia. Não naturais, tais critérios são resultado de disputas pela fixação de determinados paradigmas de gosto. No entanto, o trabalho de Bourdieu é todo baseado na noção de campo, que trata de esferas de produção de saber, como a arte, ciência e matemática. Elas possuem suas próprias regras de funcionamento, além de se caracterizarem pela reivindicação de autonomia, ou seja, ingerência a determinantes externos.

O exemplo da arte é ilustrativo: pela libertação econômica e social da tutela da aristocracia e da Igreja, que até então definia seus valores éticos e estéticos, o 
campo artístico se torna autônomo, sendo capaz de construir os próprios critérios de produção e julgamento (BOURDIEU, 2005). Vale notar que a autonomia nunca é absoluta, mas nem por isso é menos importante como propriedade de funcionamento dos campos. As instâncias de seleção e consagração específicas deixam isso claro: ainda que subordinadas a pressões econômicas, como no caso das editoras, elaboram julgamentos e escolhas baseadas em códigos e valores próprios, inacessíveis externamente.

Ao estudar objetos como a música eletrônica ou hip-hop, é necessário cautela, pois as relações com a mídia e o mercado tornam suas fronteiras muito mais fluidas que os campos estudados por Bourdieu, que tendem à conservação e fechamento. Nas cenas, o impulso à mudança e a relação com determinantes externos é essencial, o que impede colocar a questão da autonomia da mesma forma.

Este artigo, portanto, investiga o limite dos conceitos de Bourdieu para compreender as cenas musicais contemporâneas. A noção de cena remete a um "espaço cultural no qual uma gama de práticas musicais coexistem, interagindo umas com as outras através de uma diversidade de processos de diferenciação e de acordo com trajetórias amplas e variáveis de mudança e intercâmbio" (STRAW, 1991, p. 9). A utilidade do conceito está na capacidade de lidar com a fluidez dos códigos e fronteiras que caracterizam a paisagem musical contemporânea, sem cair, no entanto, na perspectiva pós-subcultural, que enxerga essa paisagem como território livre de regras e constrangimentos. Utilizada por diversos pesquisadores, a noção de cena mostra, assim, a sua relevância (AMARAL et al., 2017; HERSCHMANN, 2016; JANOTTI JUNIOR; SÁ, 2013; SOARES, 2016).

Investigar os códigos de cada cena é analisar uma série de dilemas compartilhados: que festas "valem a pena", quem são os pioneiros, quem são os recém-chegados, quem são os "vendidos para o sistema", quem são os "genuínos", de que gêneros podemos gostar, que outros gêneros precisamos odiar, que artistas devemos conhecer, que artistas temos que desprezar. A resposta a essas questões muda com o tempo e depende do jogo de forças de cada cena. Quanto maior o 
prestígio de certos grupos, maior é a capacidade de impor seus critérios de gosto como se fossem regras naturais e definitivas, escondendo, assim, o processo de lutas de que são produto.

A relação entre Bourdieu e cenas musicais já foi analisada por Sarah Thornton (1996) em Club cultures, livro que detalha a estrutura interna da cena de música eletrônica inglesa, definida como uma cultura de gosto que opera por meio da distinção social. Logo, este texto é um diálogo direto com Thornton e ainda busca se aprofundar em algumas noções de Bourdieu pouco investigados pela autora, como habitus, campo e capital social. Nosso objetivo, como um todo, é assinalar limites, barreiras e adaptações necessárias ao uso dos conceitos do sociólogo para compreender as dinâmicas musicais contemporâneas.

\section{A perspectiva sociológica do gosto}

Descobrir como determinados paradigmas de gosto tornam-se superiores a outros, denunciar a lei de formação de um bom gosto e seu correlato mau gosto é a intenção Bourdieu. A sociologia do gosto não implica rejeição à apreciação estética. O objetivo da análise científica do julgamento artístico é, sobretudo, político: ela revela como a fruição estética aparentemente desinteressada é lugar de divisões, barreiras, segregação e conflitos de poder. O gosto, "propensão e aptidão à apropriação - material e/ou simbólica - de uma determinada categoria de objetos ou práticas classificadas e classificadoras" (BOURDIEU, 2007, p. 165), envolve as tarefas de classificação e valoração por meios das quais os indivíduos posicionam os outros e si próprios no espaço social.

Assim, trava-se uma batalha "com poderes concorrentes, hostis, aliados ou neutros, os quais é preciso aniquilar, intimidar, conchavar, anexar ou coligar", na busca pela legitimidade de posições. Esta conquista se traduz na aceitação de seus discursos não como mais uma versão dos fatos, mas como a expressão da verdade, pois "se há uma verdade, é que a verdade está em jogo nas lutas, [assim, há uma] pretensão à universalidade, ao juízo absoluto" (BOURDIEU, 
1989, p. 293). Dessa forma, cria-se uma divisão entre quem "naturalmente" possui capacidade estética e os dela desprovidos.

Quando debatemos juízos de valor, acreditamos estar só expressando opiniões. Não nos damos conta de, com isso, almejar a fixação de uma verdade. Ao longo do processo, age um poder simbólico, invisível, que todos exercem e a que todos estão sujeitos, mesmo sem saber. Agindo inconscientemente, ele cria um efeito de cumplicidade, o que o torna tão poderoso. O poder simbólico é o mecanismo de construção da nossa percepção da realidade, a força que nos conforma à situação vigente, que passa a ser encarada como a ordem natural das coisas.

Assim, Bourdieu reivindica que a "sociologia deve incluir uma sociologia da percepção do mundo social, isto é, uma sociologia da construção de visões do mundo, que também contribuem para a construção desse mundo" (1990, p. 157). O mundo social é, assim, uma construção social que implica em atos de classificação e rotulamento. Os juízos de valor, que cotidianamente exprimem nossos gostos, produzem o real. Se mudarmos as formas de classificar o mundo, toda a sua estrutura, tal como a conhecemos, também se alterará.

Isso nos permite falar de dominantes e dominados: os primeiros, dotados de maior volume de capital cultural, detém o monopólio da violência simbólica, ou seja, o poder de legitimar suas concepções de mundo e torná-las aceitas pelos segundos, que a elas podem se opor, buscando fazer valer concepções alternativas dentro do mesmo campo de disputa. O processo de julgar é, assim, uma arena de disputas simbólicas. Mexer nos rótulos que designam indivíduos, espaços e produtos culturais é alterar as classificações e o sistema desigual de forças que estruturam o mundo social. Isso se exprime nas nossas corriqueiras discussões sobre gosto musical. Debater a compatibilidade de um artista a certo gênero é uma das situações mais comuns e controversas quando se discute música. 0 que está em jogo não é encontrar o nome "certo" para uma sonoridade que já existe, mas perceber que ela passa a existir no momento em que é reconhecida e, para tanto, a nomeação é fundamental. O sujeito que tem o poder de nomear demonstra autoridade cultural e capacidade de atuar como mediador de gosto. 
Até aqui, o instrumental de Bourdieu pode ser aplicado sem grandes problemas. Ao acompanharmos fóruns de discussão, comunidade virtuais, resenhas críticas ou comentários banais na saída de um show, vemos como os atores se esforçam em tecer hierarquias de valor para o que escutam. Essas simples expressões de ponto de vista encerram atos de violência simbólica, meio de se distinguir e fazer que seu paradigma de gosto se imponha socialmente.

\section{Campo}

A obra de Bourdieu tem por objetivo desvendar os mecanismos de dominação e reprodução da ordem social. A sociedade é vista como um espaço recortado por relações de poder que distanciam indivíduos, grupos, e indivíduos dentro de um mesmo grupo. O conceito de campo $(1983,1997)$ é utilizado para compreender como a realidade se estrutura a partir de relações de poder desiguais. Desse jogo de poder, participam grupos, classes e indivíduos posicionados em um campo de disputas. Um campo é "um espaço social estruturado, um campo de forças - há dominantes e dominados, há relações constantes, permanentes, de desigualdade, que se exercem no interior desses espaços - que é também um campo de lutas para transformar ou conservar esse campo de forças" (1997, p. 57). Suas "propriedades dependem das posições nestes espaços"; os campos são locais onde "se encontrará uma luta, da qual se deve, cada vez, procurar as formas específicas, entre o novo que está entrando e que tenta forçar o direito de entrada, e o dominante que tenta defender o monopólio e excluir a concorrência" (BOURDIEU, 1983, p. 89).

Podemos falar de um campo de poder global, a estruturar a própria sociedade, mas também de campos de poder específicos, como a arte, a matemática ou a ciência. Eles giram ao redor de objetos de disputa particulares, mas que obedecem a leis gerais, pautadas sobre o monopólio da violência simbólica, isto é, o poder de fabricar e impor a verdade. Os campos de produção simbólica só podem ser analisados a partir de sua conexão com o campo de poder global, na medida em que funcionam como "microcosmos da luta simbólica" (BOURDIEU, 1989, p. 12). 
As posições desiguais em seu interior são produto da distribuição assimétrica de capital, seja ele econômico (dinheiro) ou cultural (conhecimento), o que permite aos grupos e indivíduos o acesso diferenciado a pré-requisitos para o usufruto de bens da cultura legítima. As classes sociais ocupam, aqui, um papel central, já que organizam o acesso desigual ao conhecimento legítimo e às formas legítimas de se julgar. Mas as classes não são realidades evidentes: elas precisam antes ser construídas.

A classe (ou o povo, ou a nação, ou qualquer outra realidade social de outro modo inapreensível) existe se existirem pessoas que possam dizer que elas são a classe, pelo simples fato de falarem publicamente, oficialmente, no lugar dela, e de serem reconhecidas como legitimadas para fazê-lo por pessoas que, desse modo, se reconhecem como membros da classe, do povo, da nação ou de qualquer outra realidade social que uma construção do mundo realista possa inventar e impor (BOURDIEU, 1990, p. 168).

Nesse sentido, quando analisamos determinada cena musical, é necessário detectar que tipo de variável social dá acesso a posições de poder. Muitas vezes o protagonismo não é da classe, mas do gênero, etnia, geração etc. Detectada a variável central, é necessário perceber como ela se constrói. Assim, além de afirmar a centralidade da classe, para o punk, e do gênero, para as riot grrrls, é necessário perceber como essas noções se plasmam em rituais e símbolos específicos. No caso das riot grrrls, trata-se de uma variante do punk feita por mulheres. O trabalho de Gottlieb e Wald (1994) mostra como, através de roupas, cortes de cabelo, declarações na mídia e, fundamentalmente, de canções com ritmo acelerado, distorções, gritos e letras que falam de aborto, incesto e lesbianismo, um grupo de feministas deu início a uma cena musical cujo objetivo era contestar a noção do rock como gênero "essencialmente" masculino. Assim, compreender esses códigos e manuseá-los de acordo com os parâmetros definidos pelo grupo é o pré-requisito para ser reconhecido nesse universo.

Isso evidencia como as cenas musicais também são guiadas por regras próprias e definições do que, internamente, se toma por cultura legítima. No 
entanto, isso não faz que a noção de campo e cena se alinhem facilmente. 0 trabalho de Bourdieu lida muito melhor com a conservação da ordem do que com sua mudança. Mesmo que ele tenha analisado casos excepcionais de revolução simbólica, cristalizados na figura de Manet, na pintura (1989), e Flaubert, na literatura (2005), o impulso dominante no campo é a conservação. A tradição mostra seu peso, atuando por meio de instituições e agentes que buscam manter as hierarquias sociais estabelecidas.

Nas cenas musicais, o peso da tradição não é de todo desprezível, mas a mudança faz parte da ordem cotidiana, dispensando revoluções para ocorrer. Estilos musicais e artistas estão a todo o tempo em ciclos de queda e ascensão. A noção de cena busca capturar as lógicas que escapam ao conceito de comunidade, preocupado com manifestações construídas ao redor de uma localidade que tenha tradição e estabilidade como valores centrais. As cenas não dizem respeito a todo o tipo de manifestação musical contemporânea, mas àquelas em que a pluralidade de sentidos e a lógica dos cruzamentos é mais central que a reivindicação da força das raízes e mitos de origem (STRAW, 1991, 2006).

A noção evidencia como as atividades usuais de escutar música, conversar e dançar são repletas de códigos e sentidos ocultos. É necessário, portanto, desvendar o que está em jogo nessa ordem, repleta de hierarquias e mecanismos de distinção. Logo, não é possível pensar as cenas enquanto campos, mas podemos utilizar certas propriedades dos campos para pensálas, já que ambos são locais de disputa simbólica. Os códigos que organizam as cenas - quais são os artistas em ascensão e declínio, as gravadoras proeminentes, quem é indie, quem é mainstream, quais os festivais mais populares - decorrem dessa disputa, evidenciando uma assimetria de poderes. Seus limites e fronteiras não possuem a mesma rigidez dos campos, mas ainda são de grande importância para se compreender as lógicas que organizam os mapas musicais contemporâneos. 


\section{Ortodoxos e heterodoxos}

A estrutura das cenas deriva do poder desigual de seus agentes, o que depende de sua autoridade e seu capital cultural. A tentativa de conservação e subversão dos valores dominantes convive lado a lado. Assim, se instaura "uma luta, da qual se deve, cada vez, procurar as formas específicas, entre o novo que está entrando e que tenta forçar o direito de entrada e o dominante que tenta defender o monopólio e excluir a concorrência" (BOURDIEU, 1983, p. 89). Dela participam ortodoxos e heterodoxos. Os primeiros buscam manter os limites do campo, bem como sua hierarquia de poder, enquanto os segundos tentam subvertê-las.

Como dissemos, a noção de cena enfatiza os cruzamentos, e não os mitos de origem. Isso não quer dizer que tais mitos sejam desprezíveis. Na cena de música eletrônica, o techno de Detroit e o house de Chicago, estilos que se construíram nos anos 80 , até hoje se mantém como mitos de origem, sustentados por DJs e entusiastas que cultuam os "pais fundadores". Isso mostra que, mesmo em gêneros que abraçam as novas tecnologias, uma certa imagem de "raiz" se mantém, ainda que ela esteja a todo tempo em tensão com novos estilos e agentes que a resgatam ou desafiam (GARSON, 2009).

Uma cena musical depende de uma série de agentes (músicos, bandas, empresários, jornalistas, donos de casa noturna) e instituições (gravadoras, veículos de comunicação, lojas de disco) que lhe dão suporte. A chegada de novas sonoridades e agentes obriga a estrutura vigente a reorganizar-se para os acolher, o que sinaliza possíveis perdas de prestígio aos atores dominantes. Artistas que afirmam que sua sonoridade é "de raiz", que "não se vendem ao sistema", ou que "sua música tem história" agem de forma conservadora, idealizando um passado que teria se corrompido. Eles visam controlar as subversões e interferências para não serem prejudicados com a mudança dos sistemas de atribuição de lucros simbólicos já estabelecidos nas cenas.

Em sentido oposto, estão os heterodoxos: os recém-chegados que buscam subverter os esquemas vigentes, forçando o reconhecimento de procedimentos não 
legitimados pelo grupo. Podem comportar também figuras já estabelecidas, que tencionam os limites firmados. Quando cruzam os espaços de circulação legítimos e são acusados de "se prostituir" e "se vender ao sistema", retrucam acusando os ortodoxos de "elitistas" ou "esnobes". Com isso, esses agentes denunciam as bases em que o discurso de dominação se assenta, mostrando sua parcialidade e evidenciando que a ordem estabelecida só se perpetua ao ser sustentada por uma estrutura de agentes que dela obtêm lucros simbólicos.

\section{Habitus}

Para compreender a lógica que está na origem da maneira como os indivíduos classificam a realidade social, é preciso ter claro o conceito de habitus, um "sistema de posições duráveis, estruturas estruturadas predispostas a funcionar como estruturas estruturantes" (BOURDIEU, 1987, p. 15), isto é, "sistema de esquemas de produção de práticas e também sistema de esquemas de percepção e apreciação das práticas" (BOURDIEU, p. 158). O conceito explica como a representação que os agentes fazem do mundo social - o modo como avaliam e classificam a realidade - é consequência da posição que ocupam nesse espaço desigual, que é a interiorização mental de suas barreiras sociais. O habitus age de forma inconsciente; assim, é "coletivamente orquestrado sem ser o produto da ação combinada de um maestro" (BOURDIEU, 1974, p. 15).

O habitus se forma a partir de certos limites impostos pelo campo, construindo-se ao longo de nossa vida. Sua ação tem início bem cedo no meio familiar. Sendo um resultado da ação prática dos indivíduos no mundo, possui um componente individual, atrelado à trajetória de vida de cada sujeito, mas também coletivo, produto de coerções estruturais que posicionam os indivíduos de forma desigual no espaço social. A ação do habitus independe de vontade ou consciência individuais.

O habitus, então, é o mediador entre indivíduo e sociedade: ele explica como o agir individual está condicionado por constrangimentos sociais que, ao serem internalizados, passam a guiar a ação dos sujeitos no mundo. A sociedade 
deposita toda sua estrutura desigual na mente dos indivíduos, que a transforma em categorias de distinção que orientam posicionamentos em situações particulares. As estruturas sociais tornam-se, assim, estruturas mentais, o que permite falar em "interiorização da exterioridade e exteriorização da interioridade" (BOURDIEU 1983, p. 47).

Dando primazia à ação prática do indivíduo no mundo, Bourdieu atenta às instituições como espaços constituintes de diferentes habitus. Ao partilharem condicionamentos sociais similares, o que pressupõe a ação do mesmo conjunto de instituições, os grupos de indivíduos desenvolvem esquemas de classificação (gostos) e ação semelhantes. Nesse sentido, podemos falar de habitus de classe, próprios a um determinado estrato social, mas também habitus masculino, burguês ou nacional. A escola, um dos exemplos mais estudados pelo sociólogo, é encarada como o local onde são inculcadas e naturalizadas as formas dominantes de se portar e de julgar. Ainda que possamos falar em cultura dominante, existem vários elementos - de origem social, espacial, étnica - que participam da formação do habitus, imprimindo diferenças nas formas de pensar e agir de grupos e indivíduos (BOURDIEU, 1990).

É difícil afirmar que as cenas musicais constituem algum habitus específico, pois, mesmo que elas participem da construção dos valores e laços sociais de seus participantes, não têm o poder de regular de forma durável ou permanente as tomadas de posição dos indivíduos, diferentemente do gênero e da nacionalidade. São diversos os graus de comprometimento de cada indivíduo às cenas musicais, o que resulta em uma incorporação variável de seus códigos. É bastante comum o trânsito entre diferentes cenas. Tão logo cesse o contato com alguma delas, seus valores, ainda que deixem resquícios, dificilmente terão a mesma participação na subjetividade individual. Isso já fica claro no trabalho pioneiro acerca das subculturas, em que se notava como a construção de famílias levava os indivíduos ao abandono das subculturas e dos estilos de vida que as caracterizavam (HALL; JEFFERSON, 1976).

Do conceito do habitus é útil reter a função das instituições enquanto agentes de construção e socialização dos padrões dominantes de gosto, que, por 
sua vez, orientam os agentes em suas tomadas de posição. Esses padrões se expressam na maneira como os indivíduos são recebidos na entrada de uma casa noturna, julgados pela música que escutam ou maneira como se vestem. Pelo grau de engajamento nos rituais que caracterizam as cenas - frequentar festas, bares, lojas de disco, produzir eventos, participar de comunidades virtuais - os indivíduos aos poucos incorporam seus padrões de gosto e conduta, passando a reproduzi-los inconscientemente como verdades. Interessa-nos perceber como esse mecanismo de transmissão e incorporação age nas cenas, que, mesmo não dispondo de instituições que conformem um habitus, não estão livres de lógicas de atribuição de valor.

\section{Capital cultural e social}

O volume de capital cultural de um indivíduo ou instituição faz com que seu juízo de valor seja acatado como bom ou mau gosto, evidenciando posições assimétricas de poder no mesmo espaço. Ao consumo cultural se atrelam certas maneiras legítimas de usufruto. A conformação e o poder de definir essas regras é proporcional ao prestígio de cada agente.

"Os bens culturais podem ser apropriados ao mesmo tempo materialmente - o que pressupõe capital econômico - e simbolicamente - o que pressupõe capital cultural" (BOURDIEU, 1985, p. 247). Disso deriva uma apropriação material que diz respeito a mercadorias palpáveis, e imaterial, que aponta as precondições de seu usufruto legítimo, mostrando como o consumo pressupõe um sentido, um código cultural e uma maneira de ler. Não se trata de afirmar que cada produto dispõe de uma forma consagrada de usufruto. Há um campo de possibilidades que encerra diferentes graus de legitimidade para cada uso, isto é, diferentes níveis de conformação aos usos dominantes; aqueles eleitos como "corretos", pois são produto de uma história de lutas e de atos de violência simbólica.

O ajustamento aos códigos do grupo demanda a interiorização de seus modos de apreciação e julgamento. Mesmo na análise de grupamentos juvenis contemporâneos ou cenas musicais, cujos códigos estão a toda hora se modificando, 
a autenticidade, a necessidade de soar verdadeiro ainda é bastante importante (GARSON, 2009; SÁ; GARSON; WALTENBERG, 2009). Essa capacidade só se adquire mediante o pertencimento aos grupos e engajamento em seus rituais consagrados. É pela relação que se estabelece com as instituições que os sujeitos absorvem, progressivamente, os códigos legítimos, constituindo seu capital cultural.

Buscando reconhecer a importância do capital cultural nas cenas musicais, Thornton (1996) mostra o conhecimento dos códigos legítimos sendo usado como forma de distinção. Nesse processo, os signos consumidos devem ser reconhecidos coletivamente, exibidos e postos à prova tanto na forma de comodities - capital cultural objetificado (roupas, discos, livros etc.) -, quanto na forma de discursos capital cultural incorporado (a qual festa se vai, qual DJ se conhece, qual música se escuta).

Na análise da autora, a presença maciça das mídias na cultura contemporânea - tanto as massivas quanto as segmentadas - faz delas agentes centrais na formação dos códigos culturais próprios às cenas. É por uma relação de proximidade ou afastamento com certos tipos de mídia que os integrantes das cenas musicais definem seus valores e paradigmas. Através delas, o capital cultural de um grupo é construído e distribuído, o que forja uma identidade coletiva². O esforço de Thornton atualiza a obra de Bourdieu para lidar com as configurações da cultura contemporânea.

Aqui, esbarramos mais uma vez na rigidez dos conceitos do sociólogo. A noção de capital cultural é completamente atrelada à de habitus e, portanto, sujeita às mesmas ressalvas já feitas. Ao tratar da interiorização de regras sociais, somos levados ao conceito de capital cultural incorporado: "um ter que se tornou ser, uma propriedade que se fez corpo e tornou-se parte integrante da 'pessoa', um habitus" (BOURDIEU, 1990, p. 74). Trata-se de uma inscrição inconsciente de todo o conhecimento adquirido no corpo do indivíduo que se exprime em atividades 
mundanas: falar, andar, comer. É um processo que se desenrola lentamente e tende a se perpetuar.

Esse efeito de permanência, somado à possibilidade de comandar as escolhas dos sujeitos de forma ampla, merece ser mais bem tratado. As cenas são frequentadas por públicos diversos: comportam desde quem faz da música seu elemento principal de sociabilidade até um grande número de "curiosos", que circulam em vários tipos de cena sem estabelecer laços fortes com nenhuma. É possível falar de capital cultural incorporado em relação aos primeiros, mas não aos segundos, que estão bem representados pelos já mencionados jovens entrevistados por Bennet (1999) em Glasgow, que consomem música de forma fragmentada, sem estabelecer laços fortes com nenhum estilo ou subcultura em particular.

Não se quer com isso afirmar que o público leigo, por desconhecer os códigos das cenas musicais, está a eles imune. Isso fica claro quando Thornton (1996, p. 55) menciona o caso de recém-chegados que são barrados na porta de casas noturnas por não estarem vestidos da maneira "certa", não conhecerem as músicas "certas" nem as pessoas "certas". Ao analisar uma cena musical, é necessário perceber que as disputas de gosto fazem muito pouco sentido para grande parte do público que flutua nesses espaços, sem neles se engajar. Para esses indivíduos, não há grandes incentivos para participar de disputas simbólicas ou serem reconhecidos pelos membros mais antigos. Ao tratar a cena eletrônica como uma comunidade de gosto, não diferenciando o grau de comprometimento dos diferentes segmentos de público que por ela circulam, Thornton afirma que todos os indivíduos estão igualmente atrelados às disputas simbólicas, o que é difícil de sustentar.

Outro conceito que nos ajuda a entender a dinâmica dos públicos é o de capital social: uma rede de relações sociais, uma filiação a um determinado grupo, o que pode criar reconhecimento mútuo entre seus membros, resulta em crédito e prestígio individual. O que explica a falta de prestígio dos recém-chegados é a inexistência de sujeitos que Ihes deem uma credencial dentro do grupo. O capital 
social é diretamente ligado ao capital cultural. Como este só existe a partir do momento em que é certificado pelo grupo, é necessária uma rede de relação que proceda a essa certificação. Assim, a ausência de capital social também age em prejuízo do capital cultural. O que pode parecer uma simples escolha - ir à festa A ou $B$, ler a revista $X$ ou $Y$, acessar o site $C$ ou $D$ - impõe-se como verdadeira obrigação para manter o status adquirido e fazer jus à imagem construída no grupo.

Como o capital é fruto direto do reconhecimento social, ele é bastante frágil, pois supõe acumulação lenta e gradual, mas é facilmente perdido quando o indivíduo se engaja em práticas não legitimadas pelo grupo. O que diferencia os indivíduos dentro de uma cena musical é a importância que os rituais ocupam na constituição de sua identidade individual, determinando o engajamento não só inconsciente, mas também voluntário, nas disputas simbólicas que regem tais espaços. No caso dos recém-chegados, é baixo o capital social e cultural, o que Ihes põe à margem das disputas e obrigações impostas aos estabelecidos. Assim, o poder e a influência das regras de uma cena musical não afetam igualmente os indivíduos.

\section{Considerações finais}

Apesar de efêmeras, híbridas e plurais, as cenas musicais na contemporaneidade ainda são passivas de análise. Para tanto, recorremos a Bourdieu. No entanto, como sua obra é toda baseada em esferas de produção de conhecimento cuja lógica de reprodução e conservação é mais importante que a mudança, é necessário sublinhar uma série de limites e adaptações. Encorajando a aplicação dos conceitos do sociólogo a objetos que operam numa chave diferente, este artigo buscou sinalizar uma forma possível de adaptação, que tenta contornar a rigidez de certas noções, mas também não mutila por completo seu sentido original. Nesse percurso, resgatamos o trabalho de Thornton, a fim de verificar em que medida certas noções de Bourdieu, não aprofundadas em seu trabalho, podem nos ajudar, e de que maneira suas interpretações, apesar de instigantes, deixam a desejar em alguns pontos. 


\section{Referências}

AMARAL, A. et al. Mapeando cenas da música pop: cidades, mediações e arquivos. João Pessoa: Marca de Fantasia, 2017.

BENNETT, A. Subcultures or neo-tribes? Rethinking the relationship between youth, style and musical taste. Sociology, Thousand Oaks, v. 3, n. 3, p. 599-617, 1999.

BOURDIEU, P. A economia das trocas simbólicas. São Paulo: Perspectiva, 1974.

. Algumas propriedades dos campos. In: Questões de sociologia. Rio de Janeiro: Marco Zero, 1983. p. 89-94.

. The forms of capital. In: RICHARDSON, J. Handbook of theory and research for the sociology of education. Nova York: Greenwood, 1985. p. 241-258.

. O poder simbólico. Rio de Janeiro: Bertrand Brasil, 1989.

. Espaço social e poder simbólico. In: . Coisas ditas. São Paulo: Brasiliense, 1990. p. 149-168.

. Sobre a televisão. Rio de Janeiro: Zahar, 1997.

As regras da arte. Rio de Janeiro: Companhia das Letras, 2005. A distinção: crítica social do julgamento. São Paulo: Zouk, 2007.

COHEN, P. Subcultural conflict and working-class community. In: THORNTON, S.; GELDER, K. (Org.). The subcultures reader. Londres: Routledge, 1997. p. 149-62. 
GARSON, M. Quem é o melhor DJ do mundo: disputas simbólicas na cena de música eletrônica. 2009. Dissertação (Mestrado em Comunicação) - Universidade Federal Fluminense, 2009.

GOTTLIEB, J.; WALD, G. Smells like teen spirit: riot grrrls, revolution, and women in independent rock. In: ROSE, T.; ROSS, A. (Org.). Microphone fiends: youth music and youth culture. Nova Iorque: Routledge, 1994.

HALL, S.; JEFFERSON, T. (Ed.). Resistance through rituals: youth subcultures in postwar Britain. Londres: Hutchinson, 1976.

HERSCHMANN, M. Construindo uma cena musical independente em Niterói no início do século XXI: o estudo de caso dos coletivos Arariboia Rock e Ponte Plural. E-Compós, Brasília, v. 17, n. 1, 2014. 20 p.

JANOTTI JUNIOR, J.; SÁ, S. P. (Orgs.). Cenas musicais. São Paulo: Anadarco, 2013.

MUGGLETON, D. What is post-subcultural studies anyway? In: MUGGLETON, D.; WEINZIERL, R. (Orgs.). The post-subcultures reader. Oxford: Berg, 2003. p. 3-23.

POLHEMUS, T. No supermercado do estilo. Contracampo, Niterói, v. 35, n. 2, p. 7-12, ago./nov. 2016.

SÁ, S. P.; MARCHI, L. de. Não basta ser DJ: tem que ser underground! Famecos, Porto Alegre, v. 12, n. 16, p. 56-67, abr. 2005.

SÁ, S.; GARSON, M.; WALTENBERG, L. Música eletrônica e rock entre ruídos e riffs: gêneros musicais em tempos de hibridismo. In: BORELLI, S. ; FREIRE FILHO, J. (Org.). Culturas juvenis no século XXI. São Paulo: Educ, 2009. p. 171-194. 
SOARES, T. Recife não é Belém, brega não é tecnobrega. In: CONGRESSO DE CIÊNCIAS DA COMUNICAÇÃO NA REGIÃO NORDESTE, 18., 7-9 jul. 2016, Caruaru. Anais... [S.I.]: Intercom, 2016.

STRAW, W. Systems of articulation, logics of change: scenes and communities in popular music. Cultural Studies, Londres, v. 5, n. 3, p. 361-375, 1991.

Scenes and sensibilities. E-Compós, Brasília, ago. 2006. 16 p.

THORNTON, S. Club cultures: music, media and subcultural capital. Londres: Wesleyan University Press, 1996.

submetido em: 21 dez. 2017 | aprovado em: 27 fev. 2018 